\title{
Consumer Understanding and Satisfaction Associated With a 3-Tier Prescription Drug Benefit
}

\author{
BRIDGET M. OLSON, PharmD, MS; DANIEL C. MALONE, PhD, RPh; \\ WOODIE M. ZACHRY, PhD, RPh; and STEPHEN JOEL COONS, PhD
}

\begin{abstract}
OBJECTIVE: The purpose of this research was to investigate consumer understanding and satisfaction associated with a 3-tier prescription drug benefit among users of the prescription drug benefit.

METHODS: This study involved a self-administered postal questionnaire and the use of prescription drug claims to evaluate utilization of prescription medications. Fifteen hundred subjects were randomly selected based on the following inclusion criteria. Each subject had to (1) be enrolled in a 3-tier copayment (\$10 generic, \$20 formulary brand, \$35 nonformulary brand) prescription drug benefit; (2) be the primary beneficiary (cardholder); (3) be >18 years of age; (4) have received at least 1 prescription medication using his or her prescription drug insurance; and (5) have a mailing address on file.

RESULTS: A total of 479 usable responses were returned (35\% response rate). The mean (SD) understanding score was 2.22 (1.54) (range: 0 to 6). Fewer than $1 \%$ of respondents correctly answered all 6 items used to measure the level of understanding. The mean (SD) satisfaction score was 54.32 (19.69) (range: 0 to 100). Experience with purchasing a medication within a particular copayment tier was predictive of correctly answering the item related to that tier's copayment amount. Multiple regression analysis revealed a relationship between the amount of use of the drug benefit and the degree of satisfaction with the drug benefit. There was no significant relationship between the level of understanding and the degree of satisfaction with prescription drug insurance.

CONCLUSION: The average level of beneficiary understanding of the 3-tier copayment prescription drug benefit was very low, and the average degree of respondent satisfaction appeared to be near neutral. There was no significant relationship between the level of understanding and the degree of satisfaction with prescription drug benefits. The level of understanding was proportional to the amount of drug benefit use, but the degree of satisfaction was not related to the amount of drug benefit use.
\end{abstract}

KEYWORDS: Health care knowledge, Patient satisfaction, Health insurance, Managed care

J Manag Care Pharm. 2005;11(6):480-92

\section{Authors}

BRIDGET M. OLSON, PharmD, MS, is an outcomes liaison, and WOODIE M. ZACHRY, PhD, RPh, is an outcomes liaison consultant, Eli Lilly and Company at the time of this study, Olson was an assistant research scientist and Zachry was an assistant professor, Center for Health Outcomes and PharmacoEconomic Research, College of Pharmacy, University of Arizona, Tucson); DANIEL C. MALONE, PhD, $R P h$, is an associate professor, and STEPHEN JOEL COONS, PhD, is a professor, Center for Health Outcomes and PharmacoEconomic Research, College of Pharmacy, University of Arizona, Tucson.

AUTHOR CORRESPONDENCE: Bridget M. Olson, PharmD, MS, Outcomes Liaison, Eli Lilly and Company, 9872 Saskatchewan Ave., San Diego, CA 92129. Tel: (858) 538-5575; Fax: (858) 538-5579; E-mail: olsonsbca@mac.com

Copyright $\odot$ 2005, Academy of Managed Care Pharmacy. All rights reserved.
$\mathrm{H}$ ealth plans are continually searching for effective ways to constrain the growth in overall expenditures. One mechanism for controlling prescription medication costs is to increase the financial participation by beneficiaries. Multitiered copayments have emerged as a strategy for offering broad access to medications while simultaneously incorporating higher levels of consumer cost sharing. In general, tier copayment pharmacy benefits require the consumer (beneficiary) to pay a lower copayment amount for a generic drug, a higher copayment amount for a formulary brand-name drug, and a still-higher copayment amount for a nonformulary drug

A 3-tier benefit is typically designed such that the 2 upper copayment tiers consist of brand-name drugs, with the highest copayment applied to those medications that are either not on the health plan's formulary or those that are otherwise not preferred, such as "lifestyle" medications that might be perceived to be of less medical importance. The cost differential between the second and third copayment tiers is generally designed to be large enough to motivate drug plan beneficiaries to choose second-tier medications over those in the third copayment tier.

In 2004, the Kaiser Family Foundation reported that $68 \%$ of workers with employer-sponsored insurance coverage had at least 3 tiers of cost-sharing arrangements. ${ }^{1}$ Given the shift toward multitiered pharmacy benefit designs and the complexity of such programs, it is important to assess consumer understanding and satisfaction associated with these plans. Although limited research has been published, it appears that the majority of consumers may not understand their prescription drug benefits. ${ }^{2-6}$

Miller and Desselle reported the results of an interoffice mail survey of 1,380 employees from a large university. ${ }^{6}$ Knowledge of 4 content areas related to prescription drug benefits were assessed, including generic/brand issues, availability of provider networks, formulary considerations, and cost-sharing arrangements. These investigators concluded that the overall knowledge about prescription drug benefits was low to moderate, limiting the opportunity for empowered decision making in the current health care system.

Desselle has also investigated the relationship between consumer understanding and satisfaction as related to prescription drug plans..$^{3-5}$ Most respondents overestimated their level of understanding. Interestingly, Desselle reported an inverse relationship between beneficiary understanding of the prescription drug benefit and beneficiary satisfaction.

Ensuring that consumers understand the structure of their 
prescription drug insurance may prevent some of the confusion and/or dissatisfaction likely to develop in association with higher levels of consumer cost sharing. A first step in accomplishing this task is to measure the baseline understanding and satisfaction of consumers with respect to their prescription drug benefit. Previous studies of consumer understanding of prescription drug benefits have relied on convenience samples, ${ }^{3-5}$ consumerreported measures of understanding, ${ }^{7}$ or concentration on general terminology rather than specific benefit characteristics. ${ }^{8}$

The purpose of this research was to investigate consumer understanding and satisfaction associated with a 3-tier copayment prescription drug benefit, expanding upon previously employed methodologies (e.g., convenience sampling, assumption-based accuracy measures). By considering the outcomes reported in this investigation, providers and managers of prescription drug benefits will be better able to address consumer information needs regarding multitiered copayment plans. An enhanced appreciation for what factors do and do not seem to influence consumer understanding and satisfaction will be attained, helping decision makers identify areas that may require focused research and attention in their own organizations.

\section{Methods}

\section{Subjects}

A postal questionnaire was designed to assess consumer understanding and satisfaction associated with a 3-tier prescription drug benefit. Fifteen hundred subjects from a managed care insurance company were randomly selected to receive a selfadministered questionnaire based on the following inclusion criteria. Each subject had to (1) be enrolled in a 3-tier copayment (\$10 generic, $\$ 20$ formulary brand, $\$ 35$ nonformulary brand) prescription drug benefit; (2) be the primary beneficiary (cardholder); (3) be >18 years of age; (4) have received at least 1 prescription medication using his or her prescription drug insurance between November 1, 2001, and February 28, 2002; and (5) have a mailing address on file with a pharmacy benefit management company (PBM). Subjects were chosen without regard to race or sex. The random sample of 1,500 individuals was drawn from a sampling frame of 9,278 persons meeting the inclusion criteria for this study. The sampling procedure is outlined in Figure 1. This research was approved and conducted according to guidelines set forth by the University of Arizona Human Subjects Protection Program.

\section{Sample Size Considerations}

The sample size for this study was determined based on several factors. The sample size required to be representative of the opinions of 9,000 to 10,000 insured members is 368 to 370 respondents. ${ }^{9}$ As the population size increases, the required sample size increases at a diminishing rate; therefore, there are limited benefits to obtaining sample sizes $>380$ cases. Furthermore, a random sample of 370 persons from a population

\section{FIGURE 1 Sampling Procedure}

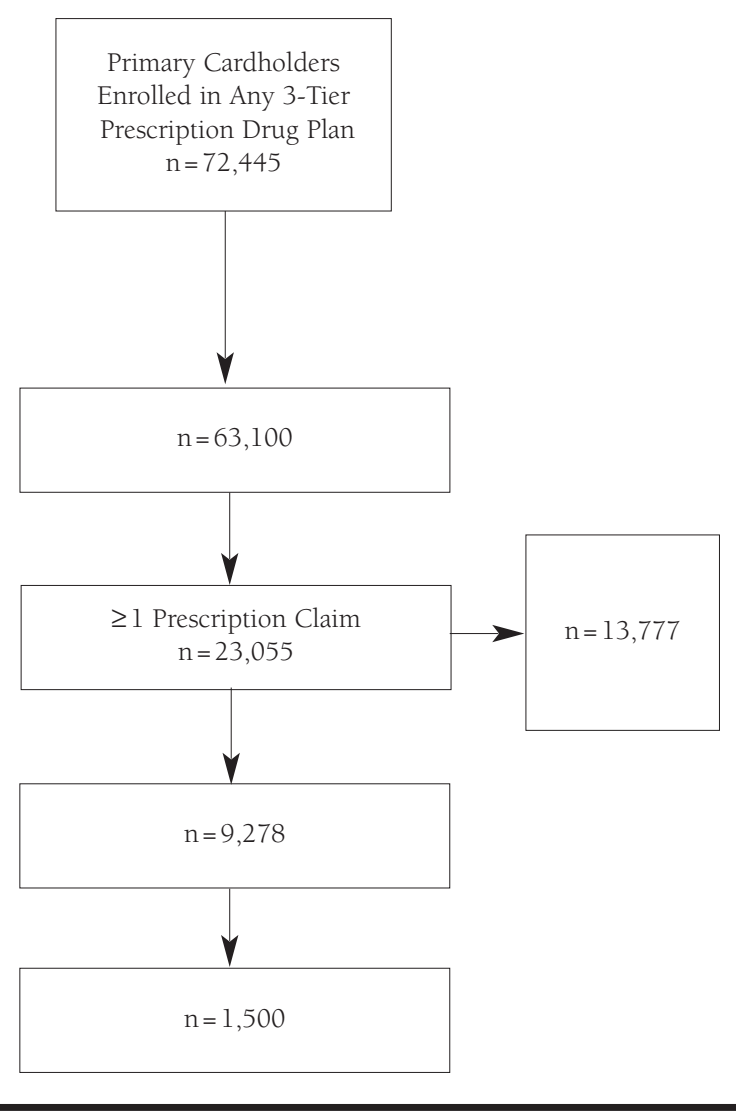

of 10,000 would result in estimates that will have a sampling error of no more than $5 \% .^{10}$

Determining how many completed responses were required to adequately test the research hypotheses in this investigation was considered..$^{11}$ The sample size was increased to account for undeliverable questionnaires. In addition, the history of low response rates previously obtained by the PBM in surveying its members as well as the personal nature of this investigation were considered. Therefore, a sample size of 1,500 was selected to allow for nonrespondents.

\section{Questionnaire Design}

A 38-item questionnaire was designed specifically for this study. Seven items were included in the questionnaire to assess general characteristics of the sample (e.g., self-reported health status, sociodemographic information). Other items focused on the types and sources of information recalled and/or utilized by respondents with respect to the pharmacy benefit ( 5 items), self-assessment of understanding ( 3 items), the impact of out-of-pocket expenses on prescription medication use (6 items), and medication utilization and expenditures 


\section{TABLE 1 Items Used to Measure Understanding and Satisfaction Associated With Prescription Drug Benefits}

\begin{tabular}{l} 
Item \\
\hline Understanding \\
\hline A deductible is a fixed dollar amount (usually \\
$\$ 250-\$ 500$ ) that a consumer must pay before their \\
prescription drug insurance becomes effective. Do \\
you have a deductible for prescription drugs? (Item 6 \\
A copay is the portion that a consumer pays for a \\
prescription at the time it is purchased. Copays can \\
be different depending on your prescription drug \\
insurance. When using your prescription drug \\
insurance to purchase prescription drugs from a \\
pharmacy, what type of copay structure do you have? \\
(Item 7)
\end{tabular}

Who do you think is ultimately responsible for determining your copay when you purchase a prescription drug? (Item 8)

Response Choices

Yes

No

Don't recall

Single copay

2-tier copay

3-tier copay

4-tier copay

5-tier copay

Other

Don't know

Pharmacist

Pharmacy owner
Health insurance company

Pharmacy benefit

management company

Employer

Other

Don't know

When you go to a pharmacy, what do you pay for

a prescription drug? In other words, what is your copay?

Generic prescription drug? (Item 9a)

Brand-name prescription drug that your insurance prefers? (Item 9b)

Brand-name prescription drug that your insurance does not prefer? (Item 9c)

\begin{tabular}{|c|c|}
\hline Satisfaction & \\
\hline $\begin{array}{l}\text { Financial coverage } \\
\text { The amount you pay for generic prescription drugs } \\
\text { (Item 10a) } \\
\text { The amount you pay for brand name prescription } \\
\text { drugs. (Item 10b) } \\
\text { Overall, the amount you pay for your prescription } \\
\text { drugs (including brand and generic). (Item 10c) } \\
\text { Your insurance's contribution towards your } \\
\text { prescription drug costs. (Item 10d) }\end{array}$ & $\begin{array}{l}\text { Very satisfied } \\
\text { Satisfied } \\
\text { Neither satisfied } \\
\text { nor dissatisfied } \\
\text { Dissatisfied } \\
\text { Very dissatisfied }\end{array}$ \\
\hline $\begin{array}{l}\text { Medication choice } \\
\text { The choice of drugs covered by your prescription } \\
\text { drug insurance. (Item 10e) }\end{array}$ & $\begin{array}{l}\text { Very satisfied } \\
\text { Satisfied } \\
\text { Neither satisfied } \\
\text { nor dissatisfied } \\
\text { Dissatisfied } \\
\text { Very dissatisfied }\end{array}$ \\
\hline $\begin{array}{l}\text { My prescription drug insurance limits my chances } \\
\text { of getting the best medications available. } \\
\text { (Item } 17 \mathrm{~b} \text { ) }\end{array}$ & $\begin{array}{l}\text { Strongly agree } \\
\text { Agree } \\
\text { Neither agree } \\
\text { nor disagree } \\
\text { Disagree } \\
\text { Strongly disagree }\end{array}$ \\
\hline $\begin{array}{l}\text { Availability of information } \\
\text { Availability of information about your prescription } \\
\text { drug insurance. (Item 10f) }\end{array}$ & $\begin{array}{l}\text { Very satisfied } \\
\text { Satisfied } \\
\text { Neither satisfied } \\
\text { nor dissatisfied } \\
\text { Very dissatisfied }\end{array}$ \\
\hline
\end{tabular}

(4 items). Six items were specifically designed to test respondents' comprehension of their prescription drug plan. Seven items focused on satisfaction with the pharmacy benefit.

Items related to understanding and satisfaction were patterned after those developed by Momani and colleagues, ${ }^{2}$ Desselle, ${ }^{3}$ Nair, ${ }^{8}$ Ware and colleagues, ${ }^{12}$ Marquis, ${ }^{13}$ McCall and colleagues, ${ }^{14}$ Johnson and colleagues, ${ }^{15}$ Hibbard and colleagues, ${ }^{16}$ and Tucker. ${ }^{17}$ Item development was accomplished using techniques discussed by these authors as well as by Salant and Dillman, ${ }^{10}$ Fowler ${ }^{18}$ Streiner and Norman, ${ }^{19}$ the U.S. General Accounting Office, ${ }^{20}$ and Sudman and Brandburn. ${ }^{21}$ Finally, a section was provided for respondents to provide feedback regarding the questionnaire or their prescription drug benefits.

The validity of the questionnaire was assessed to ensure that it would accurately reflect what it was intended to measure. To enhance the content validity of the questionnaire, several items were patterned after those included in previously published papers assessing consumer knowledge and satisfaction associated with health and prescription drug insurance. Several practicing pharmacists who were familiar with consumer issues related to prescription drug insurance also assessed content validity through reviews of the questionnaire. Faculty members from the University of Arizona College of Pharmacy who had extensive experience in survey research and questionnaire development were consulted throughout the development of the questionnaire, as well. Furthermore, individuals from the PBM and the insurance company who had experience in surveys conducted among their member populations and who were closely involved in the administration of pharmacy benefits offered input during the development process. Appraisals of the questionnaire by each of these individuals were used to adapt the questionnaire prior to pilot testing. Reliability was assessed by Cronbach's coefficient alpha. The questionnaire was then pilot tested in 21 subjects to check for comprehension and ease of completion prior to distribution.

\section{Items Related to Understanding of the Prescription Drug Benefit}

Six items were included in the questionnaire for the specific purpose of testing respondents' understanding of the basic benefits provided by the insurance company's 3-tier copayment (\$10/\$20/\$35) prescription drug plan (Table 1). Each of these 6 items was associated with a single correct answer by which all responses were compared. Only respondents answering all 6 test items were given an overall tested understanding score. Respondents were asked to report if their plan required a deductible be paid before their prescription drug insurance would become effective. They were also asked to indicate in which type of copayment structure they were enrolled and to indicate who was ultimately responsible for setting the prescription copayment amounts established under their benefit. Finally, respondents were asked the copayment amounts associated with 3 different types of prescription drug classifications covered 
under their plan (i.e., generic, preferred brand name, and nonpreferred brand name). The questions contained pertinent definitions, explaining the basic meanings of "deductible" and "copay," as well as the 3 copayment levels. These simple explanations were included to avoid measuring misunderstanding of the question as opposed to misunderstanding of the basic aspects of the prescription drug benefit.

\section{Items Related to Satisfaction With the Prescription Drug Benefit}

A series of items asked respondents to assess their level of satisfaction (on a 5-point response scale from very satisfied to very dissatisfied) with respect to specific aspects of the prescription drug benefit. These items were related to financial coverage, medication choice, and availability of information. With respect to financial coverage, respondents were asked to rate their level of satisfaction with the required copayments for generic medications, brand-name medications, and overall copayments. Satisfaction with the insurance company's contribution toward prescription drug costs was also assessed. The specific questions for assessing satisfaction are detailed in Table 1.

\section{Questionnaire Administration}

One week before the questionnaire was mailed, an announcement postcard was sent to all subjects informing them of the survey and requesting them to consider participating. The questionnaire was mailed in April 2002, followed by a reminder postcard one week later. A second copy of the questionnaire was sent to all subjects who had not responded within 3 weeks of the initial mailing of the questionnaire.

\section{Prescription Drug Claims Information}

The number of prescription claims processed for each primary beneficiary and the total number of prescription claims processed on the family level were obtained from the PBM. Total expenditures occurring during the study period (January 1 , 2002, through May 31, 2002); generic, preferred brand name, and nonpreferred brand-name prescription drug utilization; mail-order use; and geographic region were also provided.

\section{Statistical Analysis}

All statistical analyses were performed using SPSS 11.0 for Windows, Intercooled Stata 6.0 for Windows, and Microsoft Excel and were evaluated using a conventional 2-tailed alpha $(\alpha)$ level of 0.05.22-24 While much of this investigation was descriptive in nature, bivariate and regression analyses were also conducted.

\section{Descriptive Statistics}

In order to calculate scores for tested understanding and satisfaction, respondents were required to have completed all items used in calculating those measures. Therefore, understanding was calculated only for those individuals who completed all 6 test items. For the understanding dimension, responses were dichotomously coded as 0 (incorrect) or 1 (correct). The total number of correct responses achieved out of the 6 test items was recorded as the understanding score for each respondent. Similarly, an overall satisfaction score was calculated only for those individuals who completed all satisfaction items. One item (17b, Table 1) was negatively worded; therefore, it was reverse-scored so that the higher scores indicated a higher level of satisfaction. For ease of interpretation, scores for each item were standardized to a scale of 0 to 100 . A composite satisfaction score for each respondent was calculated by summing across the mean satisfaction scores for each of the 3 dimensions, then dividing by 3 . This composite score was used to describe each respondent's level of satisfaction with the prescription drug benefit. The mean number of correct responses (i.e., understanding) and the composite satisfaction scores are reported accordingly.

\section{Bivariate Statistics}

In many cases, the variables collected in this investigation were either ordinal, not normally distributed, or demonstrated nonlinear relationships. Spearman rank-order correlations were, therefore, performed. The independent group $t$ test or Mann-Whitney U test were used to assess associations between continuous dependent variables (i.e., understanding and satisfaction) and dichotomous independent variables, including sex (male/female), race/ethnicity (white/nonwhite), and U.S. region (Northeast-Midwest/Southwest), where appropriate. In this study, the levels of education and income were each measured using an ordinal scale; therefore, the Kruskal-Wallis test was used. In cases where the Kruskal-Wallis test was significant, a series of Mann-Whitney U tests were performed in order to determine which groups were significantly different. An adjusted $\alpha$ was used to determine statistical significance under these multiple comparisons in order to maintain the overall type I error rate at its desired level (i.e., $P=0.05$ ).

\section{Regression Analyses}

Multiple linear regression analyses were conducted to assess the relationships between potential predictors (i.e., independent variables such as sociodemographic characteristics) and the dependent variables (i.e., understanding and satisfaction). The assumptions of linearity, normality, homoscedasticity, and independent residuals were tested. In addition, multiple logistic regression analysis was used to determine if utilization of medications within a particular tier predicted understanding of that tier's copayment requirement.

\section{Results}

\section{Respondent Characteristics}

Of the 1,500 questionnaires distributed, a total of 128 subjects were removed from the sample due to lost eligibility and/or 


\section{TABLE 2 Sample Response}

\begin{tabular}{|c|c|c|}
\hline & & $\mathrm{n}$ \\
\hline $\begin{array}{l}\text { Original sample size } \\
\text { Ineligible due to lapsed coverage } \\
\text { Respondents } \\
\text { Nonrespondents }\end{array}$ & & $\begin{array}{r}1,500 \\
102 \\
21 \\
81\end{array}$ \\
\hline Returned/undeliverable questionnaires & & 26 \\
\hline \multirow[t]{2}{*}{ Total removed from original sample } & & 128 \\
\hline & Effective sample size & 1,372 \\
\hline $\begin{array}{l}\text { Number of questionnaires returned } \\
\text { Duplicate responses* } \\
\text { Unique random identification number } \\
\text { removed from returned questionnaire } \\
\text { Respondents ineligible due to lansed }\end{array}$ & & $\begin{array}{r}511 \\
3 \\
8 \\
21\end{array}$ \\
\hline $\begin{array}{l}\text { Respondents ineligible due to lapsed } \\
\text { coverage }\end{array}$ & Usable responses & 479 \\
\hline Usable responses/effective sample size & Usable response rate & $\begin{array}{l}479 / 1,372 \\
35 \%\end{array}$ \\
\hline
\end{tabular}

* The first questionnaire returned by each duplicate respondent was included in the analysis.

undeliverable questionnaires, leaving an effective sample size of 1,372 (Table 2). A total of 479 usable responses were received, yielding a response rate of $35 \%$.

The mean (SD) age for respondents was 48.54 (13.75) years, and nearly $60 \%$ were male (Table 3 ). More than $97 \%$ of respondents reported being white or non-Hispanic, and the majority indicated having either a high school degree/GED (32\%) or having some college/training beyond high school (26\%). Income level was predominately reported to be $\$ 20,000$ to $\$ 39,999$ (31\%) and $\$ 40,000$ to $\$ 59,000$ (25\%). More than three fourths of respondents reported that their health status was either good (41\%) or very good (35\%). Respondents reported a mean (SD) of 2.13 (1.82) comorbidities, with the majority (83\%) indicating that they had at least one of the listed health conditions (Table 4). The mean (SD) number of prescription drug claims per respondent over the 5-month study period was 9.14 (8.23). The mean (SD) amounts paid by respondents and by the insurance company for those prescription claims were $\$ 189.89$ (\$186.79) and $\$ 396.54$ (\$1,201.09) per respondent, respectively.

\section{Comparison of Sampling Frame and Study Sample}

In a comparison between the sampling frame $(n=9,278)$ and the effective study sample $(n=1,372)$, there were no significant differences in the distribution among the various age groups $(P=0.088)$. The proportion of males and females did not differ, nor did the geographic distribution of the groups. The mean (SD) number of claims per person was significantly higher in the sample (10.29 [10.39]) compared with the overall sampling frame $(8.44$ [8.02]) $(P<0.001)$; however, no differences were found when comparing the mean dollars paid per claim by both the member and the insurance plan. Based on these comparisons, the sample appeared to be reflective of the sampling frame from which it was selected.

\section{Comparison of Respondents and Nonrespondents}

Nonresponse error was assessed by examining differences in sociodemographic characteristics and medication utilization and expenditures among respondents and nonrespondents (Table 5). There were no significant differences between respondents and nonrespondents with respect to geographic region, prescription drug utilization, or prescription drug expenditures. Respondents were significantly older than nonrespondents (mean [SD] age 48.54 [13.75] years versus 42.66 [13.40] years; $P<0.001)$. There was also a significantly higher proportion of female respondents (41\%) compared with nonrespondents $(31 \%)(P=0.001)$.

\section{Questionnaire Response}

\section{Information Recall and Information-Seeking Behavior}

When asked whom they would most likely ask for information about their prescription drug benefit, the majority of respondents chose either a representative from the health insurance plan (35.1\%) or a pharmacist/pharmacy employee (23.0\%). According to the insurance company and the PBM, all members of this plan received information in the following formats: (1) group enrollment meeting/benefit fair, (2) a brochure detailing aspects of the prescription drug plan, (3) a letter explaining the prescription drug plan, (4) a listing of all the drugs covered by the plan, and (5) a Web site address where more information could be obtained. Respondents most often recalled receiving a brochure detailing their prescription drug insurance (56.2\%), a list of medications covered under the insurance plan (34.2\%), or a letter explaining the benefit (26.4\%).

Although a Web site address was provided on the prescription drug benefit brochure that had been distributed at the time of enrollment, fewer than $6 \%$ of respondents recalled receiving that information. More than $17 \%$ of respondents could not recall what information was provided, while another $4.6 \%$ indicated that they did not receive any information upon enrollment in the prescription drug plan. Although only 28\% of respondents reported contacting someone with questions about their benefit, $57 \%$ indicated that they wanted more information about their prescription drug benefit.

\section{Understanding}

The mean (SD) number of tested understanding items marked correctly was 2.22 (1.54) (range 0 to 6) (Table 6). Only 3 respondents $(0.7 \%)$ correctly answered all 6 understanding items, and fewer than $40 \%$ answered at least half of the understanding items correctly. The majority of respondents (76\%) correctly indicated that there was no deductible associated with their prescription drug benefit; however, only 6\% knew that their employer was ultimately responsible for determining the 
copayments for the prescription drug plan. The vast majority (79\%) incorrectly indicated that the health insurance plan (48\%) or the PBM (31\%) determined the prescription drug copayments.

As stated above, only those individuals who were enrolled in a 3-tier prescription drug benefit were surveyed. When asked more specific questions regarding their copayment structure, $36 \%$ of respondents correctly responded that they were enrolled in a 3-tier copayment structure. When asked to write in the specific copayments for generic, preferred brand name, and nonpreferred brand-name drugs under their current prescription drug benefit, between $22 \%$ and $40 \%$ of respondents provided correct responses. Thirty-two to $60 \%$ of respondents indicated that they were "not sure" what the copayment amount was for 1 of the 3 tiers.

\section{Satisfaction}

A composite satisfaction score was calculated for each respondent based on his or her satisfaction with respect to financial coverage, medication choice, and the availability of information. The mean (SD) composite satisfaction score across all respondents was 54.32 (19.69), on a scale from 0 to 100 (i.e., near neutral).

Specific to satisfaction with the financial coverage provided by their prescription drug benefit, respondents were neither strongly satisfied nor dissatisfied (Table 7). The mean (SD) rating for overall satisfaction with prescription drug copayments (i.e., both generic and brand name) was 3 (1.05), on a scale from 1 to 5 . More than one third (36\%) of respondents indicated that they were satisfied or very satisfied. With respect to copayments for generic medications (i.e., \$10), respondents indicated a higher level of satisfaction, with a mean (SD) score of 3.55 (0.98). The majority of respondents (61\%) was either satisfied or very satisfied with the plan's generic copayment amount. Conversely, the mean (SD) satisfaction with brand-name copayments (i.e., $\$ 20$ or \$35) was 2.83 (1.12), with only 34\% of respondents reporting being either satisfied or very satisfied.

Regarding satisfaction with medication choice, $44 \%$ of respondents were satisfied or very satisfied with the choice of medications covered. Fewer than 23\% of respondents indicated that the prescription drug insurance limited access to the "best" medications. Fewer than 44\% indicated that they were satisfied or very satisfied with the availability of information provided regarding their prescription drug benefit.

\section{Factors Associated With Understanding}

There was no significant relationship between understanding of and satisfaction with the 3-tier prescription drug benefit $\left(r_{s}=0.077, P=0.129\right)$. There was, however, evidence of a statistically significant positive correlation between understanding and utilization $\left(r_{s}=0.124, P=0.010\right)$. Similarly, the number of comorbidities reported by respondents was also significantly correlated with understanding $\left(r_{s}=0.095, P=0.050\right)$ (i.e., those

\section{TABLE 3 Respondent Characteristics}

\begin{tabular}{|c|c|}
\hline Characteristic & $\mathrm{n}(\%)^{*}$ \\
\hline Mean age (SD) & $48.54(13.75)$ \\
\hline $\begin{array}{l}\text { Sex } \\
\text { Male } \\
\text { Female } \\
\text { Total }\end{array}$ & $\begin{array}{r}284(59.3) \\
195(40.7) \\
479\end{array}$ \\
\hline $\begin{array}{l}\text { U.S. region } \dagger \\
\text { Northeast/Midwest } \\
\text { South/West } \\
\text { Total }\end{array}$ & $\begin{array}{r}277(57.8) \\
202(42.2) \\
479\end{array}$ \\
\hline $\begin{array}{l}\text { Race/ethnicity } \\
\text { American Indian or Alaskan Native } \\
\text { Asian or Pacific Islander } \\
\text { Black or African American } \\
\text { Hispanic } \\
\text { White, non-Hispanic } \\
\text { Another race or multiracial } \\
\text { Total }\end{array}$ & $\begin{array}{r}4(0.9) \\
1(0.2) \\
4(0.9) \\
2(0.4) \\
451(97.2) \\
2(0.4) \\
464\end{array}$ \\
\hline $\begin{array}{l}\text { Education } \\
\text { 8th grade or less } \\
\text { Some high school, but did not graduate } \\
\text { High school graduate or general education degree (GED) } \\
\text { Some college or training beyond high school } \\
\text { 2-year college graduate } \\
\text { 4-year college graduate } \\
\text { Graduate degree beyond 4-year college degree } \\
\text { Total }\end{array}$ & $\begin{array}{r}6(1.3) \\
21(4.5) \\
150(32.3) \\
121(26.0) \\
73(15.7) \\
78(16.8) \\
16(3.4) \\
465\end{array}$ \\
\hline $\begin{array}{l}\text { Income } \\
\text { Less than } \$ 20,000 \\
\$ 20,000 \text { to } \$ 39,999 \\
\$ 40,000 \text { to } \$ 59,999 \\
\$ 60,000 \text { to } \$ 79,999 \\
\$ 80,000 \text { or above } \\
\text { Total }\end{array}$ & $\begin{array}{r}35(7.8) \\
138(30.7) \\
114(25.4) \\
68(15.1) \\
94(21.0) \\
449\end{array}$ \\
\hline $\begin{array}{l}\text { Number of comorbidities } \\
\text { Mean number reported per respondent (SD) } \\
\text { Total }\end{array}$ & $\begin{array}{r}2.13(1.82) \\
473\end{array}$ \\
\hline $\begin{array}{l}\text { Self-reported health status } \\
\text { Excellent } \\
\text { Very good } \\
\text { Good } \\
\text { Fair } \\
\text { Poor } \\
\text { Total }\end{array}$ & $\begin{array}{r}55(11.8) \\
164(35.3) \\
190(40.9) \\
49(10.5) \\
7(1.5) \\
465\end{array}$ \\
\hline Mean number of prescription claims per respondent (SD) & $9.14(8.23)$ \\
\hline Mean dollars paid per respondent out-of-pocket (SD) & $\begin{array}{r}\$ 189.89 \\
(\$ 186.79)\end{array}$ \\
\hline Mean dollars paid per respondent by insurance plan (SD) & $\begin{array}{r}\$ 396.54 \\
(\$ 1201.09)\end{array}$ \\
\hline \multicolumn{2}{|c|}{$\begin{array}{l}\text { * Totals less than } n=479 \text { resulted from questionnaire items left unanswered by responden } \\
+ \text { Based on U.S. Department of Commerce, Economics and Statistics Administration, U.S } \\
\text { Census Bureau. }\end{array}$} \\
\hline
\end{tabular}

respondents with a higher number of comorbidities scored higher on the understanding items). Respondents in higher income groups also scored higher on understanding items $\left(\chi^{2}=12.464, P=0.014\right)$. When tested in post hoc analyses, however, there were no significant differences between the 5 income 
(TABLE $4 \longdiv { \text { Self-Reported Comorbidities* } }$

\begin{tabular}{l|r|l|r}
\hline Condition & $\mathbf{n}(\%)$ & Condition & n (\%) \\
\hline Allergies or sinus problems & 179 & Diabetes or high blood sugar & 38 \\
& $(37.8)$ & & $(8.0)$ \\
Anxiety disorder & 40 & Epilepsy or seizures & 8 \\
& $(8.5)$ & & $(1.7)$ \\
Arthritis & 81 & Gastroesophageal reflux disease & 58 \\
& $(17.1)$ & (GERD) or chronic heartburn & $(12.3)$ \\
Asthma & 35 & Glaucoma & 13 \\
& $(7.4)$ & & $(2.7)$ \\
Cancer & 29 & Gout & 13 \\
& $(6.1)$ & & $(2.7)$ \\
Chest pain or angina & 25 & Heart attack or myocardial & 21 \\
& $(5.3)$ & infarction (MI) & $(4.4)$ \\
Chronic back problems & 44 & High cholesterol & 121 \\
& $(9.3)$ & & $(25.6)$ \\
Chronic obstructive & 4 & High blood pressure & 158 \\
pulmonary disease & $(0.8)$ & & $(33.4)$ \\
Chronic kidney disease & 5 & Migraine headaches & 35 \\
& $(1.1)$ & & $(7.4)$ \\
Chronic liver disease & 2 & Stroke & 4 \\
Congestive heart failure & $(0.4)$ & & $(0.8)$ \\
& $(1.7)$ & Ulcers & 20 \\
Depression & 69 & I do not have any of these & $(4.2)$ \\
& $(14.6)$ & conditions & 82 \\
* N=473; multiple responses were permitted. & \\
\hline
\end{tabular}

TABLE 5 Comparison of Respondents and Nonrespondents

\begin{tabular}{|c|c|c|c|}
\hline Characteristic & Respondents & Nonrespondents & $P$ Value \\
\hline Primary cardholders, $\mathrm{n}$ & 479 & 893 & - \\
\hline $\begin{array}{l}\text { Age, n (\%)* } \\
18-24 \\
25-44 \\
45-64 \\
65\end{array}$ & $\begin{array}{r}19(4.0 \%) \\
158(33.0 \%) \\
253(52.8 \%) \\
49(10.2 \%)\end{array}$ & $\begin{array}{r}84(9.4 \%) \\
408(45.7 \%) \\
359(40.2 \%) \\
42(4.7 \%)\end{array}$ & $<0.001$ \\
\hline $\begin{array}{l}\text { Sex, } \mathrm{n}(\%)^{*} \\
\text { Male } \\
\text { Female }\end{array}$ & $\begin{array}{l}284(59.3 \%) \\
195(40.7 \%)\end{array}$ & $\begin{array}{l}613(68.6 \%) \\
280(31.4 \%)\end{array}$ & 0.001 \\
\hline $\begin{array}{l}\text { U.S. region* }{ }^{*} \dagger \\
\text { Northeast/Midwest, n (\%) } \\
\text { South/West, n (\%) }\end{array}$ & $\begin{array}{l}277(57.8 \%) \\
202(42.2 \%)\end{array}$ & $\begin{array}{l}470(52.6 \%) \\
423(47.4 \%)\end{array}$ & 0.065 \\
\hline $\begin{array}{l}\text { Number of prescription claims } \ddagger \\
\text { (Mean/person [SD]) }\end{array}$ & $\begin{array}{r}4,377 \\
(9.14[8.23])\end{array}$ & $\begin{array}{r}7,684 \\
(8.60[9.19])\end{array}$ & $0.282 \S$ \\
\hline $\begin{array}{l}\text { Amount paid by members } \ddagger \\
\text { (Mean/claim [SD]) }\end{array}$ & $\begin{array}{r}\$ 90,956 \\
(\$ 20.78[\$ 12.57])\end{array}$ & $\begin{array}{r}\$ 150,840 \\
(\$ 19.63[\$ 10.84])\end{array}$ & $0.077 \S$ \\
\hline $\begin{array}{l}\text { Amount paid by insurance plan } \neq \\
\text { (Mean/claim [SD]) }\end{array}$ & $\begin{array}{r}\$ 189,941 \\
(\$ 43.40[\$ 123.95])\end{array}$ & $\begin{array}{r}\$ 312,202 \\
(\$ 40.63[\$ 174.42])\end{array}$ & $0.758 \S$ \\
\hline
\end{tabular}

* Pearson $\chi^{2}$ test.

† Based on U.S. Department of Commerce Economics and Statistics Administration

U.S. Census Bureau

¥t test.

$\S$ The pharmacy benefits manager did not provide the original data for

nonrespondents; therefore, nonparametric statistics could not be performed. levels at the adjusted $\alpha$ level $(P \leq 0.0025)$. Using a less conservative adjusted significance $\alpha$ level of $P=0.01$, there was a significant difference in understanding between the $<\$ 20,000$ income group and the $\geq \$ 80,000$ income group $(P=0.008)$. The mean (SD) number of tested items correctly answered was 1.69 (1.63) in the $<\$ 20,000$ group compared with 2.54 (1.51) in the $\geq \$ 80,000$ group. Understanding was not significantly associated with sex, race/ethnicity, education level, geographical region, age, or selfreported health status.

\section{Predictors of Understanding}

Results from a multiple linear regression analysis indicated that being female $(P=0.038)$ and in a higher income group $(P=0.005)$ were significant predictors of higher understanding scores. Although statistically significant $(F=1.985 ; P=0.034)$, this model did not account for a substantial amount of variance $\left(R^{2}\right.$ adjusted $\left.=0.026\right)$. Furthermore, failure to meet the primary assumptions of normality and linearity indicated that this model could not be reliably used to predict understanding of prescription drug benefits under the conditions of this investigation.

As demonstrated in logistic regression analysis, experience with obtaining a medication from any particular tier (i.e., 1, 2, or 3) was associated with a higher probability of providing the correct response for that respective tier. For instance, individuals who received at least 1 generic medication claim were 4 times (95\% confidence interval [CI], 2.03-8.03) as likely to correctly answer the generic copayment test item compared with those who did not have a claim for a generic medication. Similarly, individuals who received at least 1 preferred brand-name medication claim were 2.6 times (95\% CI, 1.46-4.49) as likely to correctly answer the preferred brand-name copayment test item compared with those who did not. Finally, individuals who received at least 1 nonpreferred brand-name claim were 3 times (95\% CI, 1.58-5.55) as likely to correctly answer the nonpreferred brand-name copayment test item compared with those who did not.

\section{Factors Associated With Satisfaction}

In this study, there were no statistically significant associations between consumer satisfaction with a 3-tier prescription drug benefit and prescription medication utilization based on the bivariate analysis. Furthermore, satisfaction did not vary by sex, race/ethnicity, education level, geographical region, age, number of reported comorbidities, or self-reported health status. Satisfaction was, however, significantly associated with income $\left(\chi^{2}=13.203 ; P=0.010\right)$, where those in higher income groups reported higher levels of satisfaction.

\section{Predictors of Satisfaction}

In a multiple linear regression analysis, greater prescription drug utilization $(P=0.01)$, higher income $(P=0.02)$, and being from the southern/western region of the United States $(P=0.03)$ 
were statistically significant predictors of satisfaction. Furthermore, despite this, less than $6 \%$ of the variance in satisfaction was explained by the variables included in the model, therefore limiting its utility. This model did pass the diagnostic criteria of normality, linearity, homoscedasticity, and multicollinearity required to adhere to the assumptions of linear regression.

\section{Respondent Comments}

While the majority of this investigation was a quantitative assessment of understanding and satisfaction associated with a 3-tier prescription drug benefit, several telling results were also obtained from respondent comments. One hundred twenty respondents provided a description of their own experiences and/or opinions concerning the prescription drug benefit (Table 8). Although the comments provided by these respondents may not represent the opinions of all participants, they certainly provide valuable insight into the concerns felt by many consumers.

\section{Discussion}

The vast majority of consumers do not understand the 3-tier pharmacy benefit plan, and satisfaction levels were near neutral in this investigation of the $\$ 10 / \$ 20 / \$ 35$ copayment design. The mean (SD) of the number of tested items answered correctly was 2.22 (1.54), with only 3 respondents (0.7\%) correctly answering all 6 tested understanding items and fewer than $40 \%$ correctly answering at least half of the tested items. There was no significant relationship between understanding and satisfaction in this investigation, and it was difficult to reliably predict either of these variables using demographic characteristics of respondents. Utilization of products within a particular tier and an increasing number of comorbidities did, however, increase the likelihood that respondents would correctly answer the copayment dollar amounts for each tier-that is, those members who had used the benefit more frequently had greater experience with the plan than those who had filled, for example, one or two prescriptions; this was reflected in their demonstration of understanding.

The current study goes a step beyond reporting general health insurance knowledge and assesses plan-specific understanding related to a 3-tier prescription drug benefit. Convenience sampling and assessment of understanding based on consumer opinion and/or assumptions regarding response accuracy may negatively influence the reliability of measured understanding. Unlike previous studies, this investigation attempted to avoid these limitations by evaluating understanding among a randomized cohort of individuals enrolled in the same 3-tier prescription drug benefit plan.

Recent research in this area by Desselle provided a wealth of information related to consumer understanding and satisfaction associated with prescription drug benefits. ${ }^{3-5}$ Most of this research was, however, conducted among a convenience sample
TABLE $6 \longdiv { \text { Responses to Understanding Items } }$

\begin{tabular}{|c|c|c|}
\hline Item Descriptions and Response Choices & $\mathrm{n}(\%)^{*}$ & Correct Response \\
\hline $\begin{array}{l}\text { Do you have a deductible for prescription drugs? } \\
\text { Yes } \\
\text { No } \\
\text { Don't recall } \\
\text { Total responses }\end{array}$ & $\begin{array}{r}49(10.5) \\
354(76.0) \\
63(13.5) \\
466\end{array}$ & No \\
\hline $\begin{array}{l}\text { When using your prescription drug insurance } \\
\text { to purchase prescription drugs from a pharmacy, } \\
\text { what type of copay structure do you have? } \\
\text { Single copay } \\
\text { 2-tier copay } \\
\text { 3-tier copay } \\
\text { 4-tier copay } \\
\text { 5-tier copay } \\
\text { Other } \\
\text { Don't know } \\
\text { Total responses }\end{array}$ & $\begin{array}{r}89(19.1) \\
101(21.7) \\
166(35.6) \\
6(1.3) \\
3(0.6) \\
5(1.1) \\
96(20.6) \\
466\end{array}$ & 3-tier copay \\
\hline $\begin{array}{l}\text { Who do you think is ultimately responsible } \\
\text { for determining your copay when you purchase } \\
\text { a prescription drug? } \\
\text { Pharmacist who fills prescription } \\
\text { Owner of pharmacy } \\
\text { Health insurance company } \\
\text { Pharmacy benefit management company } \\
\text { Employer } \\
\text { Other } \\
\text { Don't know } \\
\text { Total responses }\end{array}$ & $\begin{array}{r}38(8.6) \\
2(0.5) \\
212(47.7) \\
139(31.3) \\
28(6.3) \\
1(0.2) \\
24(5.4) \\
444\end{array}$ & Employer \\
\hline $\begin{array}{l}\text { Please write in the amount you pay for a } \\
\text { generic prescription. } \\
\text { Correct response } \\
\text { Incorrect response } \\
\text { Not sure } \\
\text { Total responses }\end{array}$ & $\begin{array}{r}174(39.2) \\
129(29.0) \\
141(31.8) \\
444\end{array}$ & $\$ 10$ \\
\hline $\begin{array}{l}\text { Please write in the amount you pay for a } \\
\text { brand name prescription drug that your } \\
\text { insurance prefers. } \\
\text { Correct response } \\
\text { Incorrect response } \\
\text { Not sure } \\
\text { Total responses }\end{array}$ & $\begin{array}{r}179(40.3) \\
116(26.1) \\
149(33.6) \\
444\end{array}$ & $\$ 20$ \\
\hline $\begin{array}{l}\text { Please write in the amount you pay for a brand } \\
\text { name prescription drug that your insurance } \\
\text { does not prefer. } \\
\text { Correct response } \\
\text { Incorrect response } \\
\text { Not sure } \\
\text { Total responses }\end{array}$ & $\begin{array}{r}98(22.1) \\
81(18.2) \\
265(59.7) \\
444\end{array}$ & $\$ 35$ \\
\hline
\end{tabular}

* Totals less than $n=479$ resulted from questionnaire items left unanswered by respondents.

of pharmacy customers enrolled in various types of insurance plans. Therefore, several assumptions were required in order to define whether some of the questions included in the knowledge assessment were, in fact, true. Momani and colleagues determined the level of consumer understanding based upon characteristics of commonly administered health plans across the United States. ${ }^{2}$ The respondents in this study were also enrolled in 


\section{TABLE 7 Satisfaction With Financial Coverage of Prescription Drug Benefit}

\begin{tabular}{|c|c|c|}
\hline Item Descriptions and Response Sets & n (\%)* & Mean (SD) \\
\hline $\begin{array}{l}\text { The amount you pay for generic } \\
\text { prescription drugs: } \\
\text { Very satisfied (5) } \\
\text { Satisfied (4) } \\
\text { Neither satisfied nor dissatisfied (3) } \\
\text { Dissatisfied (2) } \\
\text { Very dissatisfied (1) } \\
\text { Total responses }\end{array}$ & $\begin{array}{r}58(13.4) \\
205(47.2) \\
103(23.7) \\
53(12.2) \\
15(3.5) \\
434\end{array}$ & $3.55(0.98)$ \\
\hline $\begin{array}{l}\text { The amount you pay for brand-name } \\
\text { prescription drugs: } \\
\text { Very satisfied (5) } \\
\text { Satisfied (4) } \\
\text { Neither satisfied nor dissatisfied (3) } \\
\text { Dissatisfied (2) } \\
\text { Very dissatisfied (1) } \\
\text { Total responses }\end{array}$ & $\begin{array}{r}22(5.1) \\
125(28.7) \\
93(21.3) \\
146(33.6) \\
49(11.3) \\
435\end{array}$ & $2.83(1.12)$ \\
\hline $\begin{array}{l}\text { Overall, the amount you pay for your prescription } \\
\text { drugs (including brand and generic): } \\
\text { Very satisfied (5) } \\
\text { Satisfied (4) } \\
\text { Neither satisfied nor dissatisfied (3) } \\
\text { Dissatisfied (2) } \\
\text { Very dissatisfied (1) } \\
\text { Total responses }\end{array}$ & $\begin{array}{r}22(5.0) \\
138(31.7) \\
128(29.4) \\
114(26.1) \\
34(7.8) \\
436\end{array}$ & $3.00(1.05)$ \\
\hline $\begin{array}{l}\text { Your insurance's contribution toward your } \\
\text { prescription drug costs: } \\
\text { Very satisfied (5) } \\
\text { Satisfied (4) } \\
\text { Neither satisfied nor dissatisfied (3) } \\
\text { Dissatisfied (2) } \\
\text { Very dissatisfied (1) } \\
\text { Total responses }\end{array}$ & $\begin{array}{r}35(8.1) \\
155(35.8) \\
118(27.3) \\
95(21.9) \\
30(6.9) \\
433\end{array}$ & $3.16(1.07)$ \\
\hline
\end{tabular}

* Totals less than $n=479$ resulted from questionnaire items left unanswered by respondents.

various health plans, which may or may not have mimicked those plans used as the study's comparison standard.

Other studies have measured understanding of the pharmacy benefit based upon consumer opinions or general terminology without actually testing member understanding of specific benefit characteristics. For instance, Motheral and Heinle measured understanding of prescription drug benefits by asking respondents to rate their level of knowledge on a scale from "knowing nothing" to "knowing everything." Nair assessed understanding based on respondent recognition of commonly used terms associated with the administration of pharmacy benefits. $^{8}$

More recently, Miller and Desselle investigated employee knowledge of prescription drug benefits. ${ }^{6}$ In that study, a selfadministered questionnaire was distributed through interoffice mail to all full-time employees of a university. In that investigation, known benefit characteristics were used to measure respondent understanding of the plan. That is, the questionnaire was designed specifically around plan characteristics of the employee's prescription drug coverage. Aside from the current investigation, this is the only published study that has actually assessed respondent understanding based on known prescription drug plan characteristics among a defined population.

Numerous studies have examined consumer understanding of general health care issues. ${ }^{13,14,17,25-28}$ Overall, consumer awareness of having health insurance coverage has been reported to be high. In previous studies, approximately $98 \%$ of respondents correctly reported their health insurance status. ${ }^{13,28}$ It seems, however, that, as the current study found, this level of understanding dramatically decreases when specific benefit issues are examined. Newhouse and colleagues reported that cost-sharing aspects incorporated within a health plan required a higher level of sophistication or level of knowledge on the part of the consumer. ${ }^{25}$ Marquis reported that knowledge of benefits for covered services in a health plan varied with the complexity of the benefit structure. ${ }^{13}$ While most respondents in Marquis's study appeared informed about some aspects of their health insurance coverage, many lacked knowledge of the details involved in their benefit plans.

While no published studies were found that specifically assessed consumer understanding of a 3-tier benefit plan, other investigators have documented an existing gap in the general understanding of prescription drug benefits. ${ }^{3-8}$ In 2001, Desselle found that $32 \%$ of respondents knew that the number of pharmacies in their network was limited, and 28\% knew that limits existed on the types of drugs covered by their benefit. ${ }^{3}$ Most respondents (66\%) identified the insurance company as being responsible for determining their copayments. Seventyfive percent of respondents were able to differentiate between brand and generic drugs. However, fewer than 25\% were able to identify what a formulary or a preferred product was. Similar results were reported in a subsequent publication by Desselle. ${ }^{5}$ Although not reporting an overall understanding score for the population studied in the manner of the current investigation, this study demonstrated that there are substantial disparities in consumer knowledge with respect to prescription drug benefits. Again, convenience sampling and variation among participant plans may have influenced the results of Desselle's investigation.

In 2005, Miller and Desselle described the results of using both true-false and multiple-choice versions of a questionnaire to assess consumer understanding of the prescription drug benefit among a consensus sample at a university. ${ }^{6}$ The majority of respondents in this study were able to accurately distinguish between generic and brand medications as well as to recognize common terminology (e.g., copay). Similar to the current investigation, these investigators found that the overall knowledge about pharmacy benefits was low to moderate when measured against actual plan-specific benefit characteristics.

In bivariate analyses of the current study, there was evidence to support a significant relationship between utilization and understanding as well as the number of comorbidities reported 
by respondents. Individuals who received at least 1 generic preferred brand or nonpreferred brand were 2.6 to 4 times as likely to correctly answer that specific tier's copayment test item compared with those who had not received a medication in that respective tier. These results support the finding that experience with purchasing prescription medications using the prescription drug benefit was predictive of member awareness of copayment requirements. Similarly, Motheral and Heinle reported that greater prescription drug utilization was associated with knowing more about the pharmacy benefit plan. ${ }^{7}$ Sex and income were significant predictors of understanding in the current study; however, a very limited amount of variance in understanding was explained by including satisfaction, utilization, sex, race/ethnicity, education, income, geographical region, age, number of reported comorbidities, or self-reported health status in the regression analysis.

Miller and Desselle did not find significant associations between knowledge of the pharmacy benefit and the number of prescriptions filled within 30 days. ${ }^{6}$ There were also no significant associations between understanding and age, sex, education, receipt of verbal information describing prescription drug coverage, perceived health status, or health plan type. When analyzed in a multivariate regression analysis, however, acknowledged receipt of written information, perceived excellent understanding of the pharmacy benefit, and having a graduate or professional degree were positively related to knowledge for the true-false questionnaire respondents. Self-reported income and perceived fair, good, and excellent understanding of benefits were positively related to knowledge scores for multiple-choice questionnaire respondents.

Researchers in future investigations should focus on the type of information provided to the consumer and the methods for communicating that information. If specific efforts are made to systematically identify the most successful methods for educating consumers about their prescription benefit, the ultimate goal of improving understanding is more likely to be achieved.

In the current investigation, satisfaction with the pharmacy benefit was assessed based on financial coverage, access to medications, and availability of information. Respondents indicated a near neutral level of satisfaction with the $\$ 10 / \$ 20 / \$ 35$ drug benefit plan across these dimensions. Nair and colleagues reported the findings of an investigation in which member satisfaction with 2-tier and 3-tier prescription drug benefit plans was compared. ${ }^{29}$ Consistent with the current study, the mean satisfaction scores reported by Nair were between 5 and 6 (on a 10-point scale), indicating that overall satisfaction with the pharmacy benefit plans under study was not very high. There was a clear difference in satisfaction between plans, with 2-tier plan members expressing higher levels of satisfaction, largely driven by cost-sharing requirements.

In the current study, income was the only variable significantly associated with satisfaction scores in bivariate analyses. In the

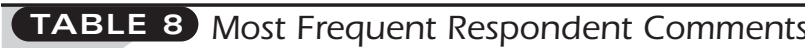

\begin{tabular}{l|l}
\hline Related to Understanding & $\mathbf{n}$ \\
$\begin{array}{l}\text { Confusion about copayments under the 3-tier plan } \\
\text { Frustration with copayments changing frequently }\end{array}$ & 21 \\
Information provided often confusing & \\
\hline $\begin{array}{l}\text { Requested additional information about the 3-tier plan } \\
\text { Need for more "user-friendly" formats }\end{array}$ & 12 \\
$\begin{array}{l}\text { Information about preferred versus nonpreferred brand medications } \\
\text { Information about brand/generic alternatives }\end{array}$ & \\
Request for copayments to be printed on insurance cards & \\
Knowing actual cost of prescription may increase perceived "value" & \\
of benefit & \\
\hline
\end{tabular}

\section{Related to Satisfaction}

Frustration with insurance company's ability to dictate coverage Lack of consideration to reduce copayment when brand required by physician

Inconvenience of day-supply limitations

Dissatisfaction with cost of medications

General comments of satisfaction with insurance company

Savings achieved when utilize mail order services

Coverage and service satisfaction (e.g., ability to afford medications because of coverage)

\begin{tabular}{l|l}
\hline Problems with mail-order services & 5 \\
\hline $\begin{array}{l}\text { Overall feeling of dissatisfaction with delivery of insurance } \\
\begin{array}{l}\text { Frustration with lack of coordination between PBM and } \\
\text { insurance company* }\end{array}\end{array}$ & 3 \\
\hline
\end{tabular}

* In the questionnaire, the pharmacy benefits manager (PBM) was merely referred to as "the company that manages the prescription drug insurance for your health insurance company." However, in the survey announcement postcard, cover letters, and reminder postcards, the specific PBM was named for recipients, followed by the description "the company that manages your prescription drug benefits for your insurance company (specific company named)."

Regarding the above comments, respondents specifically referred to the PBM by name or function (i.e., prescription claims processor).

multiple regression analysis, income, prescription drug utilization, and geographic region were significant predictors of satisfaction. Despite these findings, a limited amount of the variance in satisfaction with the 3-tier drug benefit was explained in the current investigation. In general, other studies have also found limited or no relationship between demographic factors and satisfaction with prescription drug coverage..$^{3-7}$

Given that the copayment amounts in this investigation are somewhat higher than many managed enrollees have traditionally been asked to pay, it may be somewhat encouraging to insurers and employers to see this neutral level of satisfaction. With that said, providers of prescription drug insurance should realize that confusion among consumers with respect to their pharmacy benefit may lead to increasing levels of frustration. This frustration may translate into deteriorating satisfaction-a measure by which these plans are frequently compared. Furthermore, Motheral and Heinle found that the strongest determinant of satisfaction was the level of cost sharing required of the member. ${ }^{7}$ 
The small amount of explained variation in satisfaction in this study may have been due to the lack of inclusion of variables specific to cost sharing. Since all respondents were members of the same 3-tier prescription drug benefit, it could not be determined how varying levels of cost sharing may have affected member satisfaction. Focusing more on the impact of specific plan characteristics on satisfaction, as opposed to consumer characteristics, is more likely to provide information that can help insurers anticipate how satisfaction will be impacted based on the decisions they make regarding the benefit packages they offer.

In this investigation, there was insufficient evidence to conclude that a relationship existed between respondent understanding and satisfaction associated with the 3-tier prescription drug benefit. No relationship was found in bivariate or regression analyses. Because of the low number of correctly answered understanding items across all respondents, there may have been a "floor effect," which could have limited this study's ability to identify a significant relationship between these 2 variables.

Conflicting evidence regarding the relationship between understanding and satisfaction in health care has been presented in previous studies. ${ }^{3,4,7,17}$ Tucker reported a significant relationship between understanding and satisfaction with managed care coverage in bivariate analyses; however, the study was unsuccessful at confirming this relationship after controlling for sociodemographic characteristics. ${ }^{17}$ In Tucker's study, understanding was defined by respondent-reported ratings focused on levels of comprehension and/or confusion with respect to their health plan. Again, the method of measuring understanding and satisfaction in this investigation may have created biases in interpreting the results. Satisfaction was measured by responses to one item that asked respondents to indicate their level of agreement with the statement, "I am satisfied with the health care that I received." More specific to prescription drug benefits, Motheral and Heinle also found that patient-reported understanding was not significantly related to member satisfaction. ${ }^{7}$

Desselle reported that those individuals who were less informed about formulary or drug benefit limitations overestimated their level of coverage and were, in general, more satisfied with their prescription drug benefit. ${ }^{3,4}$ While an inverse relationship between understanding and satisfaction seems to make sense, the assessment of understanding among a convenience sample of pharmacy patrons, with no means by which to verify response accuracy, may have influenced the reliability of this finding.

It does seem logical, however, to deduce that, if consumers overestimate the level of coverage provided by their prescription drug insurance, satisfaction levels can be expected to decline when reality does not match expectations. Ensuring that consumers understand the structure of their prescription drug benefits may prevent some of the confusion and/or dissatisfaction likely to develop in association with higher levels of consumer cost sharing.

As cost sharing is likely to be one of the greatest determinants of member satisfaction, this is an important area for providers of insurance to focus. While cost sharing is typically a financial necessity, cost-sharing expectations as well as rationale should be made transparent to the consumer in order to avoid surprising the member with an unforeseen - and unwelcome-financial obligation. One method of accomplishing this goal may be to test multiple methods for informing consumers about their prescription drug benefits and to compare the success of those methods as measured by increased consumer understanding. Perhaps, if consumers feel that they have been involved in the process and have not been surprised by high copayments, then they may better understand the financial implications involved in the purchase of prescription drugs and be better prepared to make fiscally responsible, informed decisions when using their benefit.

\section{Need for Improving Consumer Understanding}

In this study, respondents made several suggestions with respect to methods for improving consumer understanding about prescription drug benefits. These included (1) periodic meetings with employees and representatives from the health insurance company to clarify and/or introduce changes in coverage, (2) access to customer service representatives who are familiar with their specific plan, (3) printing of copayments on the insurance card, (4) follow-up phone calls from the insurance company or other entity familiar with their plan following changes in coverage, (5) summaries or outlines explaining the role of the insurance company in conjunction with Medicare benefits, and (6) a disclosure of the actual cost of prescription medications. These suggestions are consistent with the findings described above, indicating that, most importantly, consumers do not want to be surprised by their financial obligations in purchasing prescription drugs.

To become active participants in controlling health care costs, consumers should receive information from multiple sources (e.g., physicians, health plans, pharmacists). ${ }^{30}$ According to a survey of employers across the United States, the employees themselves hold the key to achieving significant health care cost savings. ${ }^{31}$ Interestingly, however, only a small percentage of these employers provide any specific information directly to their employees regarding insurance-related issues, such as the financial and health consequences of noncompliance with prescription medications.

Enhanced understanding on the part of the consumer can be accomplished by continuous informational endeavors. For consumer cost-sharing benefit designs (e.g., multitiered prescription drug insurance) to succeed in controlling costs while maintaining quality health care, consumers need to be educated about these benefits. They must understand their coverage, the actual cost of the services received, and the mechanisms for saving money for themselves and their health plan or employer. Informing the consumer beyond a superficial 
introduction to their benefit package is critical. Information that is easy to use, readily accessible, and updated frequently should be provided to consumers.

It has been said, "If it is true that knowledge is power, then many consumers in today's health care marketplace are in trouble."'32 There is an enormous need to inform consumers on fundamental issues pertaining to their health care so that they have the ability to make intelligent choices.

\section{Limitations}

The limitations of this study should be considered when interpreting these results. First, the responses gathered in this investigation may not be generalizable to other health plan environments across the United States. The results should especially not be generalized to vulnerable patient populations (e.g., Medicaid recipients) since the effects of higher levels of cost sharing may be dramatically different in those patient populations that are not subject to significant cost sharing. Second, there was also a difference between respondents and nonrespondents: more respondents were older and female compared with nonrespondents ( 49 vs. 43 years $[P<0.001]$ and $41 \%$ vs. $31 \%$ female $[P=0.001])$. Historically, older age and being female have been associated with higher utilization of prescription medications and health care in general, which may explain why these subpopulations were more interested in responding to the survey. ${ }^{33}$

Third, although the cover letter received by plan members clearly indicated that the primary cardholder was to complete the questionnaire, it is also possible that a spouse or other family member provided responses. This may also explain the overrepresentation of older persons and females. Aside from these differences, respondents and nonrespondents did not differ with respect to geographic region, prescription drug utilization, or prescription drug expenditures. While statistical differences between respondents and nonrespondents based on age and sex were identified, the practical importance of these differences is not clear.

Fourth, measuring the level of drug benefit understanding can be a matter of interpretation. For example, in many situations, the correct answer to the question, "Who do you think is ultimately responsible for determining your copay when you purchase a prescription?" can be either the PBM or the insurance (managed care) company. While it is true that the employer ultimately makes the decision, it is often a decision to purchase a particular drug plan and its associated premium-not the copay specifically. For small employers particularly, only self-insured employers actually dictate specific copayment amounts. On the other hand, unions in labor negotiations with employers can dictate particular drug benefit designs and the amount of cost sharing required of beneficiaries. Managed care companies and PBMs routinely "package" drug benefits with predetermined copayment amounts. Including this variable (i.e., correct response indicator based on the question, "Who do you think is ultimately responsible for determining your copay when you purchase a prescription?") in the measure of understanding was tested in this investigation in order to ensure that incorrect answers on this particular item alone did not unfairly affect the results of the study.

Actual respondent understanding of the 3-tier prescription drug benefit may be very complicated to measure. It is possible, therefore, that the measurement of understanding in this study did not fully capture all the factors influencing actual respondent understanding of the prescription drug benefit.

Other variables that may be considered in future analyses aimed at identifying predictors of understanding of a prescription drug benefit may include the number and types of plans from which the consumer was able to choose when selecting coverage.,34 Information provided by the plan, the level of member cost sharing, and/or the extent of coverage should also be considered in future analyses. ${ }^{4}$ Furthermore, the impact of various methods for communicating information (e.g., brochures, pocket cards, phone calls, regular benefit updates) to members regarding their prescription drug benefits is an important area of future research.

\section{Conclusion}

In this investigation, understanding of the 3-tier prescription drug benefit was found to be extremely limited. Fewer than 1\% of respondents correctly answered the 6 items used to measure understanding, and fewer than $40 \%$ of respondents received an understanding score of $50 \%$ or greater. Nearly $57 \%$ of respondents indicated that they want more information regarding their prescription drug insurance.

In addition to a substantial lack of understanding, respondents indicated a near neutral level of satisfaction with the 3-tier prescription drug benefit. Increased utilization was associated with a higher level of understanding, indicating that exposure to a specific aspect of the plan (e.g., generic copay) increases consumer understanding of the prescription drug benefit-that is, education by experience was the most important predictor of understanding. Actual utilization of the drug benefit was not related to the degree of member satisfaction, and the level of understanding was not related to the degree of satisfaction.

\section{ACKNOWLEDGMENTS}

The authors thank Duane McKinley, RPh, and Heather Haupert, MS, for their assistance in completing this project.

\section{DISCLOSURES}

Funding for this research was provided by the Division of Pharmaceutical Policy, University of Arizona, and by an unrestricted educational grant from the Merck Company Foundation, the philanthropic arm of Merck and Co., Inc., Whitehouse Station, NJ, and was obtained by authors Bridget M. Olson, Daniel C. Malone, Woodie M. Zachry, and Stephen Joel Coons. Malone and Coons are employed by the University of Arizona, and Olson and Zachry were employed by the University of Arizona at the time of this study. The authors disclose no potential bias or conflict of interest relating to this article. Results of this study were presented in part as a poster at the 15th Annual AMCP Meeting and Showcase, April 9-12, 2003, Minneapolis, MN 
Olson served as principal author of the study. Study concept and design, analysis and interpretation of data, drafting of the manuscript and its critical revision, and statistical expertise were contributed by all authors.

\section{REFERENCES}

1. The Henry J. Kaiser Family Foundation. Prescription drug trends, October 2004. Available at: http://www.kff.org/rxdrugs/3057-03.cfm. Accessed June 10, 2005.

2. Momani A, Odedina F, Rosenbluth S, Madhavan S. Drug-management strategies: consumers' perspectives. J Manag Care Pharm. 2000;6(2):122-28.

3. Desselle SP. Patient satisfaction with and knowledge of their prescription drug coverage. J Manag Care Pharm. 2001;7(1):34-42.

4. Desselle SP. Determinants of satisfaction with prescription drug plans. Am J Health Syst Pharm. 2001;58:1110-19.

5. Desselle SP. Consumers' lack of awareness on issues pertaining to their prescription drug coverage. J Health Soc Policy. 2003;17(3):21-39.

6. Miller MJ, Desselle SP. Employee knowledge of a managed pharmacy benefit in a large corporation. Manag Care Interface. 2005;18(1):33-42.

7. Motheral BR, Heinle SM. Predictors of satisfaction of health plan members with prescription drug benefits. Am J Health Syst Pharm. 2004;61:1007-14.

8. Nair K. Evaluation of health and pharmacy benefit information in health plan information packages. Manag Care Interface. 2001;14(12):51-54.

9. Krejcie RV, Morgan DW. Determining sample size for research activities. Educ Psychol Meas. 1970;30:607-10.

10. Salant P, Dillman D. How to Conduct Your Own Survey. New York, NY: John Wiley and Sons, Inc.; 1994.

11. Bourque LB, Fielder EP. The Survey Kit: How to Conduct Self-Administered and Mail Surveys. Thousand Oaks, CA: Sage Publications, Inc.; 1995.

12. Ware J, Snyder M, Wright W, et al. Defining and measuring patient satisfaction with medical care. Eval Program Plann. 1983;6:247-63.

13. Marquis MS. Consumers' knowledge about their health insurance coverage. Health Care Financ Rev. 1983;5(1):65-80.

14. McCall N, Rice T, Sangl J. Consumer knowledge of Medicare and supplemental health insurance benefits. Health Serv Res. 1986;20(6):633-57.

15. Johnson JA, Coons SJ, Hays RE, et al. A comparison of satisfaction with mail versus traditional pharmacy services. J Manag Care Pharm. 1997;3(3): 327-37.

16. Hibbard JH, Jewett JJ, Engelmann S, et al. Can Medicare beneficiaries make informed choices? Health Aff. 1998;17(6):181-93.

17. Tucker J. Patients' knowledge of health plan coverage and satisfaction with care. Am J Manag Care. 2001;7(5):453-59.

18. Fowler F. Survey Research Methods, 2nd ed. Newbury Park, CA: Sage Publications, Inc.; 1993.
19. Streiner D, Norman G. Health Measurement Scales: A Practical Guide to Their Development and Use. 2nd ed. New York, NY: Oxford University Press; 1995.

20. U.S. General Accounting Office, Program Evaluation and Methodology Division. Developing and Using Questionnaires. Washington, D.C.: U.S. General Accounting Office; 1993.

21. Sudman S, Bradburn N. Asking Questions: A Practical Guide to Questionnaire Design. 1st ed. San Francisco, CA: Jossey-Bass, Inc.; 1982.

22. SPSS 11.0 for Windows [computer software]. Chicago, IL: SPSS, Inc. 2001.

23. Intercooled Stata for Windows Version 6.0 [computer software]. College Station, TX: Stata Corporation; 2002.

24. Microsoft Excel 97 [computer software]. Redmond, WA: Microsoft Corporation; 1997.

25. Newhouse J, Ware J, Donald C. How sophisticated are consumers about the medical care delivery system? Med Care. 1981;19(3):316-28.

26. Reis J, Olson L. The Medicaid program and consumer needs: a survey among residents of a poor Chicago neighborhood. Public Health Rep. 1987; 102:530-38

27. Ryan SA, Millstein SG, Kang M, et al. Adolescents' knowledge of their health insurance coverage. J Adolesc Health. 1998;22(4):293-99.

28. Nelson D, Thompson B, Davenport N, Penaloza LJ. What people really know about their health insurance: a comparison of information obtained from individuals and their insurers. Am J Public Health. 2000;90(6):924-28.

29. Nair KV, Ganther JM, Valuck RJ, et al. Impact of multi-tiered pharmacy benefits on attitudes of plan members with chronic disease states. J Manag Care Pharm. 2002;8(6):477-91.

30. Miller W. Promising strategies help employers integrate pharmacy and medical programs and reap cost, quality advantages. Empl Benefits J. 2001;23-27.

31. National Business Coalition on Health (NBCH). Employer survey shows employee involvement in their own care management as best way to battle increasing health care costs. October 12, 2001 [news release]. Available at: http://www.nbch.org/resources/news101201.cfm. Accessed June 21, 2005.

32. Isaacs S. Consumers' information needs: results of a national survey. Health Aff. 1996;15(4):31-41.

33. Centers for Disease Control and Prevention. Utilization of ambulatory medical care by women: United States, 1997-1998. Hyattsville, MD: U.S. Department of Health and Human Services. DHHS Publication no. (PHS) 2001-1720; 2001.

34. Gawande A, Blendon R, Brodie M. Does dissatisfaction with health plans stem from having no choices? Health Aff. 1998;17(5):184-94. 